Research Article

\title{
Effect of Hemp Fibre Surface Treatment on the Fibre-Matrix Interface and the Influence of Cellulose, Hemicellulose, and Lignin Contents on Composite Strength Properties
}

\author{
Mohammad Mazedul Kabir (D), ${ }^{1}$ Mohammad Yousef Alhaik (D), ${ }^{1}$ Saud Hamad Aldajah (D), \\ Kin Tak Lau $\mathbb{D},{ }^{2}$ Hao Wang $\mathbb{D}^{3},{ }^{3}$ and Md Mainul Islam $\mathbb{D}^{3}$ \\ ${ }^{1}$ Faculty of Engineering, Higher Colleges of Technology, Abu Dhabi, UAE \\ ${ }^{2}$ Swinburne University of Technology, Melbourne VIC 3122, Australia \\ ${ }^{3}$ Centre for Future Materials and School of Mechanical and Electrical Engineering, University of Southern Queensland, \\ Toowoomba, QLD 4350, Australia
}

Correspondence should be addressed to Md Mainul Islam; mainul.islam@usq.edu.au

Received 22 July 2021; Revised 20 October 2021; Accepted 28 October 2021; Published 30 November 2021

Academic Editor: Carlo Santulli

Copyright (c) 2021 Mohammad Mazedul Kabir et al. This is an open access article distributed under the Creative Commons Attribution License, which permits unrestricted use, distribution, and reproduction in any medium, provided the original work is properly cited.

\begin{abstract}
Natural fibres have recently become an attractive alternative to synthetic fibres in the implementation of polymer composite structures. Inherent flaws within natural fibres in terms of their constituent contents (hemicellulose, cellulose, and lignin) reduce the compatibility of these fibres with polymer matrices. In this study, the effects of chemical treatments on hemp fibres and the resulted polyester matrix composite are investigated. The fibres were treated with alkali $(0-10 \% \mathrm{NaOH})$, acetyl, and silane chemicals. Long unidirectional fibre composites were prepared by vacuum-assisted resin transfer moulding (VARTM) process. Thermal properties of the fibres were tested using differential scanning calorimetry (DSC) analyses. The mechanical properties of the composite samples were tested using compression and bending tests. Failure analysis of tested composites was undertaken through Optical Microscope $(\mathrm{OM})$ and Scanning Electron Microscope (SEM). The results showed that the treatments of the $4 \% \mathrm{NaOH}$ reduced interfacial bonding strength and decreased composite properties compared to untreated samples. At higher concentrations $(6-10 \% \mathrm{NaOH})$, the mechanical properties of the composites increased as a result of greater interfacial bonding. Different trends were observed in the case of alkalised fibres that were further treated with acetyl and silane treatments. It was observed that the treated fibres effectively improved the bonding properties of composites and was in agreement with the micrographs.
\end{abstract}

\section{Introduction}

Natural fibres are potential alternative material resources that have the ability to replace synthetic fibres in engineering fibre composites [1]. The successful utilisation of natural fibres as reinforcement requires pre-processing to achieve the desired mechanical properties of composites [2]. A good understanding of fibre and composite behaviour and their failure mechanisms is necessary before this material can be implemented in engineering applications. For composite preparation, it is desirable to have fibre surfaces which can facilitate strong bonding with the matrix. Composite properties depend greatly on the quality of interface bonding to overcome the intrinsic weaknesses of the structure $[3,4]$. Weak bonding limits the efficiency of the composite's load bearing performance and leads to under-utilisation of material properties. Chemical treatments on the fibre can improve interface bonding with the matrix which ultimately enhances the overall load bearing capacity of the composites $[2,5,6]$.

Studies indicate that natural fibres display large variations in properties, as their structures are highly affected by contemporary environmental factors such as climate change. These factors result in natural fibres developing inconsistent 
cross-sectional areas and shapes along their lengths, which affect the ultimate loads that can be carried by them $[2,4,7,8]$. Another major drawback when using natural fibres is that their structure absorbs atmospheric moisture which makes the fibre hydrophilic in nature. Hydrophilic fibres are incompatible with hydrophobic polymers (thermoset and thermoplastics) $[1,9,10]$. Therefore, natural fibres display poor fibre-matrix interfacial bonding which results in poor composite mechanical properties. The structure of natural fibre consists of three main constituents, i.e., cellulose, hemicellulose, and lignin [2]. Celluloses are considered as the major framework component of the fibre which is covered and interconnected by the hemicellulose and lignin $[8,11]$. The cellulose structure of the fibres is distinguished through crystalline and amorphous regions, whereas hemicellulose and lignin are completely amorphous [2]. In cellulose crystalline region, large numbers of strongly linked hydroxyl groups are present. These hydroxyl groups are inaccessible and so other chemicals have difficulty penetrating the crystalline region [12]. However, in the amorphous region, the hydroxyl groups are loosely linked with the fibre structure and are relatively free to react with other chemicals. Due to this freedom, hydroxyl groups present in the amorphous region can easily combine with water molecules from the atmosphere. The hydroxyl groups present in the amorphous hemicellulose and lignin initially give access to water molecules to penetrate the fibre surface [10]. Water molecules then combine with the hydroxyl groups that are present in cellulose (in the amorphous region) and stay in the fibre structure. This makes the fibre hydrophilic and polar in character $[2,10]$. The moisture absorption of fibres can be reduced by eliminating the hydroxyl groups in the amorphous region from the fibre structure through different chemical treatments [13]. The incorporation of natural fibres into a matrix is often associated with poor fibre compatibility as their cellulose surface is covered by the hemicellulose and lignin constituents. Hemicellulose and lignin act as a weak boundary layer between the cellulose (elementary fibre) and the matrix [14]. Due to the presence of weak boundary layer at the fibre matrix interface, the stress distribution capacity throughout the composite area is reduced. To obtain a satisfactory performance of the composite, it is necessary to remove the weak boundary layers from the elementary fibres. A weak boundary layer can be removed by dissolving hemicellulose and lignin coverings through different chemical treatments of the fibre [15].

Chemical reagents contain functional groups that are capable of forming chemical bonds with the hydroxyl groups of the fibre, thus providing good compatibility with the matrix. Interfacial compatibility improves the stress transfer at the interface and leads to the improvement of mechanical properties of the produced composites. Chemical treatments such as alkalisation, acetylation, and silanisation on the fibre reduce the hemicellulose and lignin contents from the fibre thereby increasing the cellulose contents. Hemicellulose and lignin were mostly removed by the alkalisation with higher concentration of $\mathrm{NaOH}$, followed by acetylation. Silane treatment could not remove the hemicellulose and lignin, rather this treatment facilitated coupling with the fibre constituents $[2,10]$. These treatments are usually based on the use of reagent functional groups that are capable of reacting with the fibre structures thus changing their composition. Chemical treatments allow the cellulose surface to react with the matrix [16]. Due to this, strong fibrematrix interface bonding can be achieved which ultimately results in greater mechanical properties of the composites.

During alkali treatment, alkalised groups $(\mathrm{NaO}-\mathrm{H})$ react with these hydroxyl groups $(-\mathrm{OH})$ of the fibre and produce water molecules $(\mathrm{H}-\mathrm{OH})$ which are consequently removed from the fibre structure. Then, the remaining alkalised groups (Na-O-) react with the fibre cell wall and produce Fibre-cell-O-Na groups [17]. These chemical activities reduce the moisture-related hydroxyl groups (hydrophilic) and thus improve the fibres' hydrophobicity. Treatment also takes out a certain portion of hemicellulose, lignin, pectin, wax, and oil coverings (weak boundary layer) from the cellulose surface [18-21]. As a result, cellulose microfibrils are exposed to the fibre surface and can easily mix with matrix materials and form strong interface bonding which results in greater load transfer capacity of the composites. Acetyl treatment is known as the esterification method to modify the natural fibre structure. The acetyl group (CH3CO-) reacts with the hydroxyl groups $(-\mathrm{OH})$ that are present in the amorphous region of the fibre and remove the existing moisture, thus reducing the hydrophilic nature of the fibre [22]. Treatment also improves the fibres dispersion into the matrix and thus enhances dimensional stability of the composite [23]. Silane is as a coupling agent to modify the fibre surfaces. Silane molecules form a chemical link between the fibre surface and the matrix through a siloxane bridge. As a result, fibre matrix adhesion improves and stabilises the composite properties [18]. Natural fibres exhibit surface micro-pores and silane couplings act as surface coatings to penetrate the pores. In this case, silane coating is used as a mechanical interlocking material for the fibre surface.

Generally, fibres are strategically placed in the matrix with specific orientations to meet required strength and stiffness properties of the composites. The performance and load distribution of a fibre reinforced composite depends on its reinforcing fibre length, shape, orientation, content, and composition in the matrix. The uniform load distribution from matrix to fibre enhances the composite properties under different loading conditions. The reinforcement orientation is capable of changing failure mechanisms and enhancing their composite properties as desired. Long continuous unidirectional fibre, twisted fibre (yarn), woven fabrics, and short discontinuous randomly oriented fibre are commonly used as reinforcement in composites. Long and unidirectional fibre with $0^{\circ}$ orientation to the applied load provides a continuous load transfer throughout the composite area. Optimum performance from longitudinal fibre reinforced composites can be obtained if the load is applied along its fibre direction. Conversely, fibre orientation perpendicular to the loading direction $\left(90^{\circ}\right)$ possesses very low transverse stress as fibre cannot act as a primary load carrying component [24]. 
The interface is a boundary region where fibre and matrix phases come in contact with zero thickness [25]. Matrices are connected to the fibre surface by chemical reaction, absorption, and mechanical interlocking. Chemical reaction takes place between the fibre functional groups and the matrix monomers. Mechanical interlocking occurs when the liquid matrix is made to flow on the fibre surface. A strong interface is required for efficient load transfer from matrix to fibre to enhance the composites' mechanical properties [26]. Interface bonding strength can be evaluated through different mechanical property analyses of the composites under different loading conditions. Under the tensile loading, the matrix plays a minor role, whilst fibre can sustain higher tensile load parallel to the fibre direction. In the case of compression loading, the matrix prevents the fibres from buckling. Generally, unidirectional fibre composites are stronger in tension but weaker in compression $[27,28]$. The combination of tension and compression produces friction due to the fibre sliding from the surrounding matrix and exhibiting shear properties. During bending, the composite undergoes tension, compression, and shear deformation. Composite property can also be investigated through micro-structural analysis by using an optical microscope (OM) and scanning electron microscope (SEM). The use of a reflected-light (OM) and infraRed (SEM) beam provides insight through detailed analysis of the fibre surface, degree of fibre matrix interface bonding, failure mechanisms, etc. [24].

This paper focuses on the effect of chemical treatments on hemp fibres, and the associated quality of interface bonding will be illustrated through a composite mechanical property analysis. In this analysis, alkali $(0 \%, 4 \%, 6 \%, 8 \%$, and $10 \% \mathrm{NaOH}$ ), acetyl, and silane treatments on hemp fibres were used. Long unidirectional hemp fibre composites were prepared by VARTM process. Interface bonding was examined through compression and bending testing. A possible sequence of failure initiation and propagation is explained through the analysis of stress-strain relationships and microscopic observations. The failure surfaces of the tested samples were examined through the Optical Microscopy (OM) and Scanning Electron Microscope (SEM).

\section{Experimental Methods}

2.1. Materials. Hemp fibres (Cannabis sativa L) approximately $1 \mathrm{~m}$ in length were obtained from Eco Fibre Industries, Australia, and were used to produce unidirectional fibre composites.

2.2. Fibre Surface Treatments. Alkaline, acetyl, and silane treatments on hemp fibres were performed. Alkaline treatment used $0 \%, 4 \%, 6 \%, 8 \%$, and $10 \% \mathrm{NaOH}$ solution. Alkali pre-treated fibres were further treated with acetyle treatment and silane treatment. The details of fibre treatment processes were outlined in a previous article [8].

2.3. Differential Scanning Calorimetry (DSC). DSC analysis is used to determine the energy released or absorbed via chemical reactions of the fibre constituents during heating. A series of exothermic and endothermic reactions take place during sample decomposition at different temperatures [29]. The magnitude and location of the exothermic and endothermic peaks indicate the thermal phase transformation of the fibre. In the case of an endothermic event, heat is absorbed by the sample, whereas heat is released in an exothermic event. Endothermic reactions provide information on sample melting, phase transitions, evaporation, dehydration, and pyrolysis. Exothermic reactions provide information on crystallisation, oxidation, combustion, decomposition, and chemical reactions [30].

DSC analysis on treated fibres was performed by using a thermal analyser (DSC Instrument, Model No. Q100). Sample preparation and heating rate were applied in the same manner as seen in TGA. The experiment was conducted in a nitrogen environment purged at $20 \mathrm{~mL} / \mathrm{min}$. Nitrogen was used for efficient heat transfer and removal of volatiles from the sample.

2.4. Composite Manufacturing Process. Hemp fibre polyester composites were prepared by utilising the VARTM process. In VARTM, fibre and matrix are mixed in a mould covered by a flexible plastic vacuum bag. Mould covering prevents the exposure of volatile organic matter to humans during sample preparation. Vacuum pressure, used in the VARTM process, removes air voids from individual fibre spacings and facilitates thorough fibre mixing with the matrix. Proper sealing of the vacuum bag on to the mould ensures void-free composite fabrication. Figure 1 presents a schematic diagram of the VARTM process for composite preparation. During composite processing, two rectangular flat glass plates $\left(1000 \times 1000 \mathrm{~mm}^{2}\right)$ were used as a mould. The glass moulds were utilised to maintain a consistent thickness throughout the samples, with smooth surface finishes being achieved in the final composites. Initially, the glass moulds were waxed several times with a mould releasing agent (Meguiars Universal Mould Release Wax, item number 88). Unidirectional fibres $(100 \mathrm{~g})$ were placed $\left(600 \times 600 \mathrm{~mm}^{2}\right)$ between the glass moulds. A distribution media layer was placed on the top of the fibres to allow effective flow of the matrix across the fibres. The mould (glass-fibre) assembly was then covered with a vacuum bag and sealed with adhesive tape. Two ports were created in the mould; a matrix inlet port and a vacuum port. The complete mould assembly was then depressurised via the vacuum port. All air voids present in the assembly were removed by vacuum pressure $(92 \mathrm{kPa})$. At this stage, the matrix inlet port was opened to allow the liquid polyester (mixed with the $1.5 \mathrm{wt} \%$ MEKP catalyst) to enter into the depressurised mould. The polyester matrix spread quickly into the mould and mixed with the fibres. Once the fibres were fully impregnated with the matrix, the matrix inlet port was closed while the vacuum port was left open for an hour. The infused composite was then cured under vacuum pressure at room temperature for 24 hours. The laminate was released from the mould and kept in an oven at $80^{\circ} \mathrm{C}$ for 4 hours to post-cure. The cured panel $\left(600 \times 600 \mathrm{~mm}^{2}\right)$ was trimmed and sectioned for 


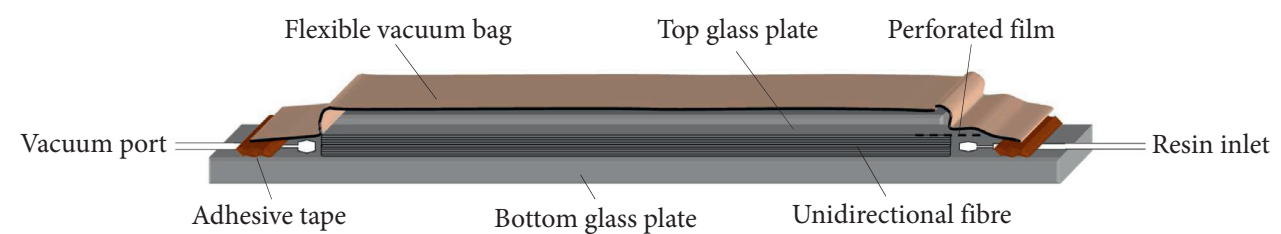

(a)

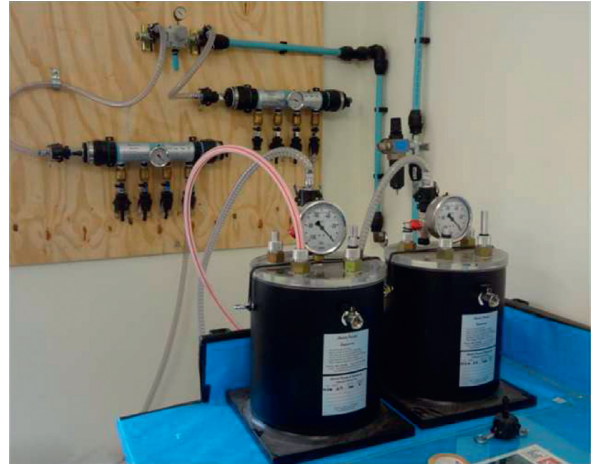

(b)

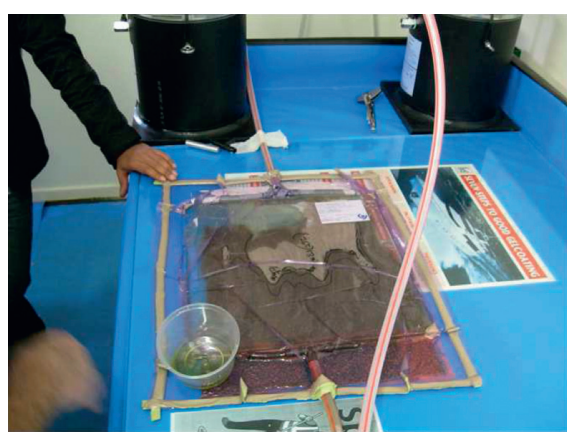

(c)

FIGURE 1: VARTM process for unidirectional fibre composites: (a) schematic diagram; (b) vacuum suction chamber; (c) sample preparation.

mechanical testing. The weight fractions of fibres were roughly $55 \%$ of the produced composites.

2.5. Compression Test. Compression testing was carried out on the unidirectional fibre composites using a $100 \mathrm{kN}$ universal testing machine (MTS) with a loading rate of $1 \mathrm{~mm} / \mathrm{min}$. For unidirectional fibre composites, the test was carried out following ISO 14126. The specimens were cut along the longitudinal fibre direction $(L \times W=140 \mathrm{~mm} \times 12 \mathrm{~mm})$ and were clamped in a Wyoming Modified Celanese Compression test fixture. The load was applied in parallel to the fibre direction and the resulting deformation was recorded until failure. After each test, the specimen was carefully removed from the test fixture and the failure mode was recorded.

2.6. Flexural Test (Three Point Bending). Flexural testing of the unidirectional fibre composite structures (following ISO 14125) were conducted using a $10 \mathrm{kN}$ universal testing machine (MTS) at a loading rate of $2 \mathrm{~mm} / \mathrm{min}$. The specimens were simply supported and tested under 3-point loading with the span set at approximately 16 times the thickness of the specimen. The load was applied at midspan of the specimens, perpendicular to the fibre direction. To determine the strength and elastic properties in bending, the load and mid-span deflection were recorded up to failure. The failure mode was also recorded after each test.

2.7. Microscopy Analysis. Optical microscopy (OM) was used to analyse the composite failure surfaces. The Olympus BX41 with a CC12 soft imaging system was used to collect images. Fibre surface morphology and the extent of fibre matrix interface bonding was analysed through Scanning
Electron Microscopy (SEM). SEM Model JSM-6400F (JEOL, Japan) was used to investigate fibre surface conditions $(20 \mathrm{kV})$ of different chemically treated fibres and their bonding with the matrix $(5 \mathrm{kV})$. Samples were placed on aluminium discs using double-sided electrically conductive adhesive tape. A conductive layer of carbon was spread on the samples' surfaces to prevent electronic charge formation. The samples were then placed in a vacuum chamber and coated with 20-30 angstroms of aluminium. A high voltage was applied on the coated samples and output images were collected for analysis.

\section{Result and Discussion}

3.1. Differential Scanning Calorimetry Analysis. The cellulose, hemicellulose, and lignin contents in chemically treated hemp fibres were determined. The detailed extraction process of the cellulose, hemicellulose, and lignin constituents from the hemp fibre was outlined in the previous article [10]. Fibre constituents (cellulose, hemicellulose, and lignin) are sensitive to the actions of different chemical reagents, treatment times, and temperatures. The changes in fibre structure can be detected by DSC analyses. DSC allows a measurement of the chemical changes of the fibre constituents when subjected to heat. Cellulose, hemicellulose, and lignin constituents showed separate peaks of decomposition which appeared through the sequence of endothermic and exothermic peaks of phase transformation at defined temperatures [31]. Endothermic peak occurred due to the volatilisation of the molecules and exothermic peak occurred due to the formation of the charring, which is the solid reside. In this study, DSC analysis was first carried out on the cellulose, hemicellulose, and lignin constituents, and then compared with untreated fibres and chemically treated fibres. 
The decomposition behaviour of fibre constituents (cellulose, hemicellulose, and lignin) and untreated fibre are presented in Figure 2. The DSC curve of cellulose showed an endothermic event at the temperature range of $10-150^{\circ} \mathrm{C}$ which was due to the evaporation of water (volatilisation) in the intercellular region of the fibre. In the temperature range of $315-360^{\circ} \mathrm{C}$, one broad endothermic event and a small exothermic event took place at around $360^{\circ} \mathrm{C}$. In the endothermic event, depolymerisation of cellulose had taken place with the formation of volatiles [10]. Hemicellulose showed an endothermic peak at the temperature range of $10-200^{\circ} \mathrm{C}$ followed by an exothermic event at $200-320^{\circ} \mathrm{C}$. During the exothermic events, the amorphous structure of hemicellulose decomposed and formed char residues [10]. The Lignin curve showed a broad exothermic peak at the temperature range of $250-450^{\circ} \mathrm{C}$. Lignin possesses aromatic rings with many branches in which a large number of chemical links exist. As a result, degradation of lignin occurs over a broad range of temperatures.

The DSC analyses of the cellulose, hemicellulose, and lignin reveals that hemicellulose has a higher endothermic peak (around $120^{\circ} \mathrm{C}$ ) compared to the cellulose (around $100^{\circ} \mathrm{C}$ ), lignin (around $95^{\circ} \mathrm{C}$ ), and the untreated fibres (around $80^{\circ} \mathrm{C}$ ). From this, it can be stated that hemicellulose absorbs more water compared to the other constituents of the fibre. This may be because the structure of hemicellulose consists of amorphous hydroxyl groups that link with water molecules from the atmosphere. Exothermal peaks of cellulose (around $360^{\circ} \mathrm{C}$ ), hemicellulose $\left(200-320^{\circ} \mathrm{C}\right.$ ), and lignin $\left(250-450^{\circ} \mathrm{C}\right)$ indicate that hemicellulose and lignin generate higher solid residues (char) compared to cellulose. Based on this, it can be stated that hemicellulose begins to degrade earlier than lignin and cellulose. Cellulose possesses higher thermal stability and lignin decomposes over broad temperature ranges. These decomposition mechanisms of fibre constituents were used to analyse the behaviour of treated fibres.

Figure 3 shows DSC curves of untreated, alkalised, acetylated, and silanised fibres. Alkalised fibre showed a higher endothermic peak (around $100^{\circ} \mathrm{C}$ ) for water evaporation compared to the untreated fibres (around $80^{\circ} \mathrm{C}$ ). This result indicates that the treatment removed hemicellulose from the fibre. A small exothermic peak appeared at the temperature range of $250-290^{\circ} \mathrm{C}$ for untreated fibres. This peak was mainly due to the decomposition of hemicellulose and a portion of lignin degradation. This exothermic peak disappeared from the alkali-treated fibres indicating that hemicellulose and lignin were removed from the fibre. Untreated fibres showed one strong exothermic peak at $300-400^{\circ} \mathrm{C}$, whereas treated fibre showed exothermic $\left(390-380^{\circ} \mathrm{C}\right.$ ) and endothermic peaks (around $360^{\circ} \mathrm{C}$ ) in this region. The initial exothermic peak on treated fibres indicated complete decomposition of the hemicellulose and the later endothermic peak indicated decomposition of the cellulose. These exothermic peak differences between the untreated and treated fibres gave further evidence of hemicellulose being removed from the fibre during alkali treatments. The acetylated fibre had higher endothermic

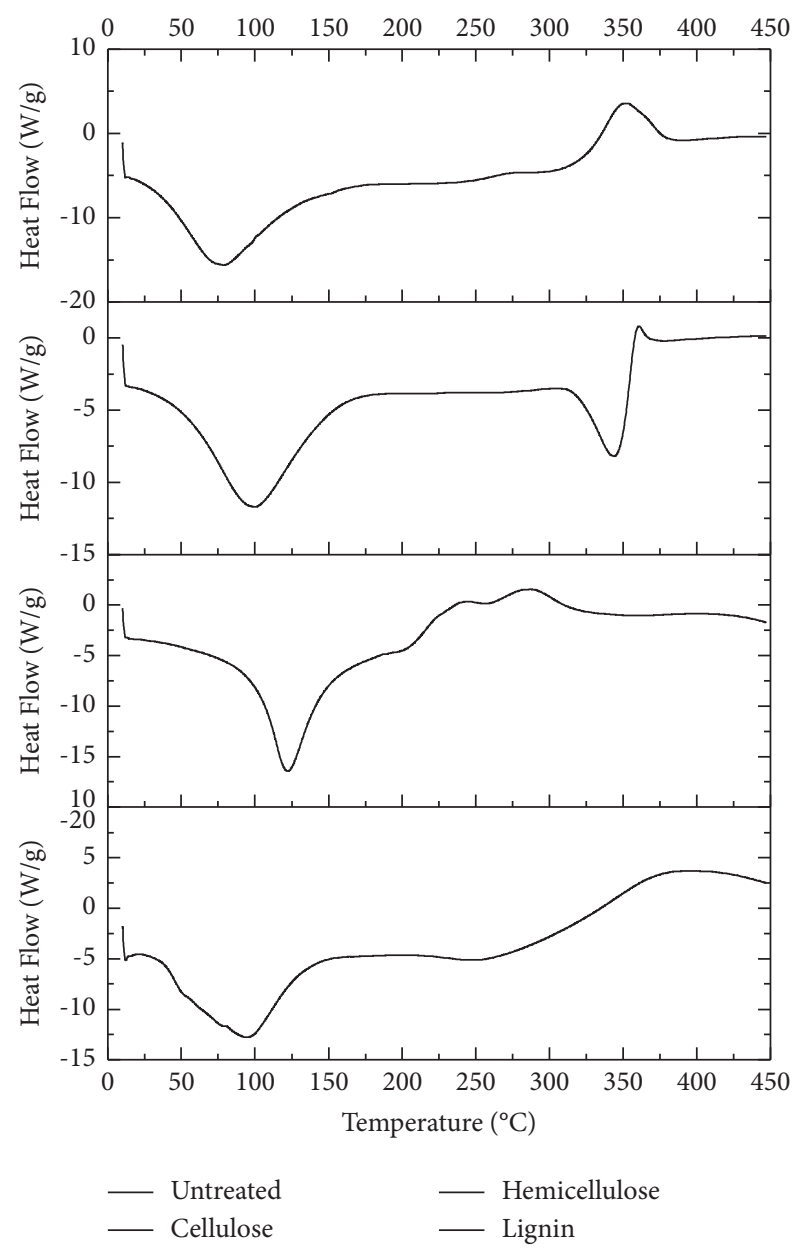

FIGURE 2: DSC curves of fibre constituents (cellulose, hemicellulose and lignin) and untreated fibre.

peaks $\left(90-110^{\circ} \mathrm{C}\right)$ compared to the untreated fibres $\left(80^{\circ} \mathrm{C}\right)$. Similar to alkalised fibres, acetylated fibres also exhibited small exothermic and endothermic peaks at the temperature range of $310-380^{\circ} \mathrm{C}$. These results indicate that acetyl treatments also remove hemicellulose and a portion of lignin constituents from the fibre. Silane treatments on the untreated fibre exhibited a higher endothermic peak temperature (around $110^{\circ} \mathrm{C}$ ) compared to the untreated fibre. This was due to the fact that silane molecules formed couplings with the hemicellulose and lignin constituents of the fibre. The water molecules held by the hemicellulose were covered by the silane coupling layers. As a result, removal of water molecules from the silane-treated fibres required higher temperatures. Therefore, silane-treated fibres had a similar DSC profile to untreated fibre at the temperature range of $230-450^{\circ} \mathrm{C}$, indicating the presence of hemicellulose on the silanised fibres. All of these results indicate that hemicellulose and lignin remained on the silane-treated fibres.

From the above analysis, it is confirmed that alkali and acetyl treatments on the fibres remove hemicellulose and lignin constituents, whereas silane formed couplings with these constituents and provided a covering on fibres protecting them from thermal degradations. 


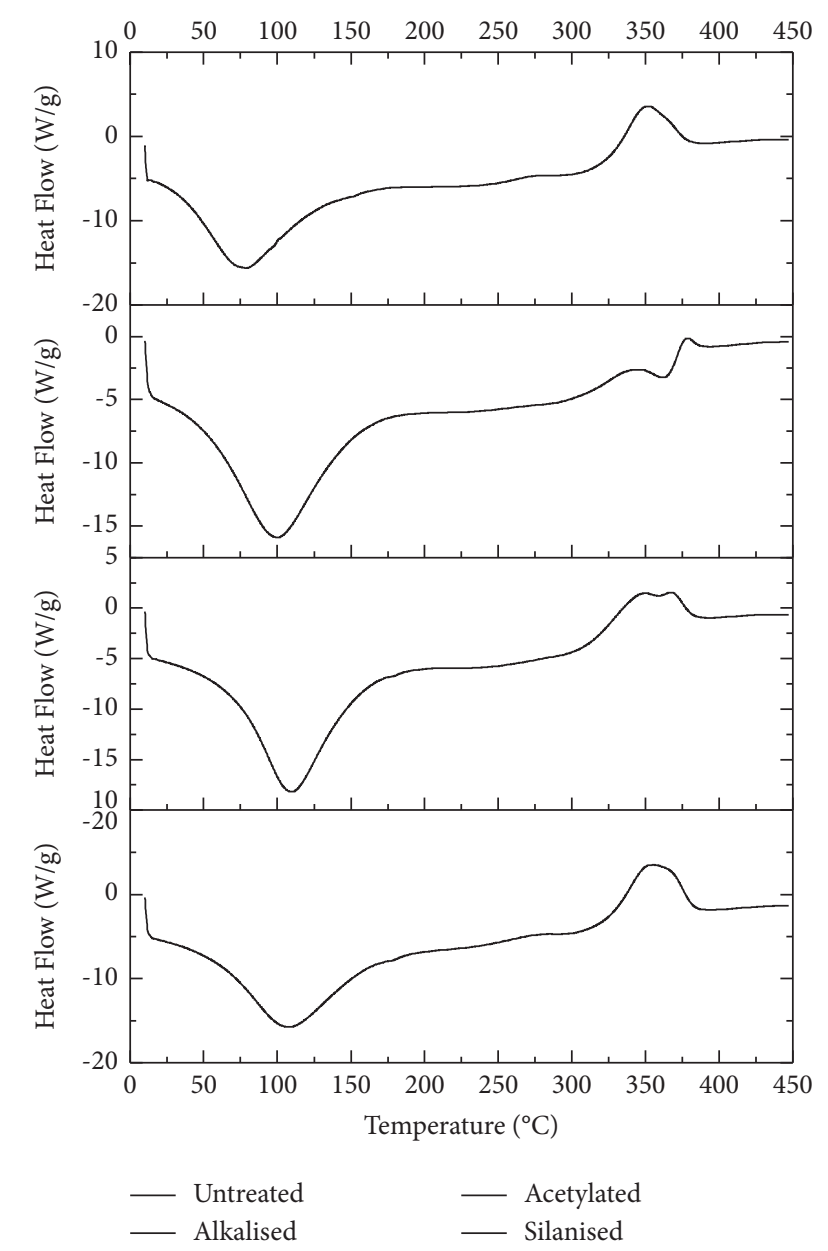

FIGURE 3: DSC curves of untreated, alkalised, acetylated and silanised fibres.

3.2. Compressive Properties of Composites. For unidirectional composites, fibres are the primary load-carrying component, while the matrix provides support to the fibres as a result of strong interface bonding. Under incremental compression loading, fibres begin to buckle at weak interface locations within the matrix [32]. Buckled fibres generate strains on neighbouring fibres and cause them to bend [28, 33]. This leads to instability along the fibre-matrix interface and generates disproportionately high stresses on the matrix [34]. As a result, the matrix shifts from pre-buckling to post buckling deformation which progressively involves damage initiation of the composites [35].

Figure 4 presents a compressive stress-strain curve for untreated fibre composite. The curve indicates that the response was linear (pre-buckling) up to strength value of $30 \mathrm{MPa}$ and strain value of 0.007 . Following this stage, the composites began to yield. As strain increased further, the curve deviated from this linear proportionality and a geometrical nonlinear response (post-buckling) increased to a stress of around $65 \mathrm{MPa}$. Finally, the failure stress point was reached. In the post-buckling path, the tangent modulus diverged in several points with different stages of modulus values. Varying recordings of modulus in the post-buckling path were due to the fact that, as the compressive loading

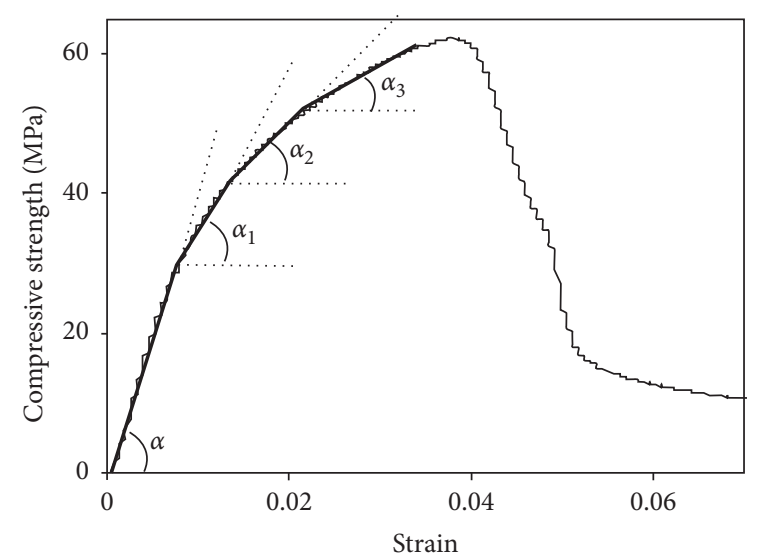

FIgURE 4: Compressive stress strain curve of the fibre composite.

increased, matrix cracks initiated and propagated along the interfaces [35]. Crack propagation gradually reduced the load carrying capacity of the composite, thereby lowering the modulus at several points on the stress-strain curve. In Figure $4, \alpha$ was the initial tangent modulus in the prebuckling state and $\alpha_{1}, \alpha_{2}$ and $\alpha_{3}$ were the tangent modulus in the post-buckling state.

3.2.1. Fibre Alkalisation on Composites. Figure 5 shows compressive stress-strain curves of alkalised fibre composites, and their properties are summarised in Table 1. From Table 1, it can be observed that alkali treatments on untreated fibres increased their associated composite strength from $69 \mathrm{MPa}$ to $75 \mathrm{MPa}$. Enhanced composite strengths were exhibited as a result of the removal of fibre surface coverings (hemicellulose and lignin) by $\mathrm{NaOH}$ treatments. SEM images show that (Figures 6(a) and 6(c)) $\mathrm{NaOH}$-treated fibre surface was cleaner compared to the untreated fibre surface. This observation clearly indicates that $\mathrm{NaOH}$ treatments could remove the hemicellulose and lignin coverings from the fibre surface. The removal of the fibre surface coverings facilitated strong interfacial bonding with matrix materials. SEM image of Figure 7(a) shows that there is a distinct separation between the untreated fibre and matrix interface, which demonstrates weak interfacial bonding of untreated fibre composites. On the other hand, Figure $7(\mathrm{c})$ shows greater fibre matrix interface bonding compared to the untreated fibre composites. These images demonstrate that a strong interface bonding was achieved due to the higher concentration of $\mathrm{NaOH}$ treatment on the fibres. Strong interfaces prevented fibre buckling, which ultimately delayed the formation of matrix cracks. Greater stress transfer from matrix to fibres took place and thus composite strengths increased.

Although alkalised fibre composites showed increased strengths, the removal of fibre surface coverings created weaknesses within cellulose microfibrils [8]. This has the effect of weakening fibres. During compression, weak cellulose microfibrils tended to buckle within the fibre. This microbuckling generated microstrains on fibres which ultimately produced extra strains at the fibre-matrix interface. 


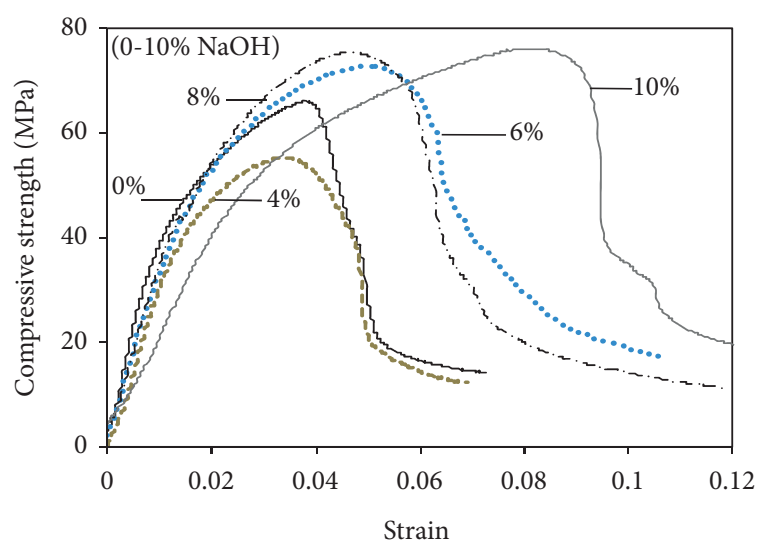

FIgURE 5: Compressive stress-strain curves for alkalised fibre composites.

The extra strain initiated microcracks at the bonded interface which gradually reduced the composites' load carrying capacity. As a result, the composite failed under large deformations. Table 1 highlights gradual increase in failure strains at higher concentrations of $\mathrm{NaOH}$ treatments (6-10\%). From Table 1, it can be seen that the post-buckling moduli $\left(\alpha_{3}\right)$ gradually decreased as $\mathrm{NaOH}$ concentration increased. This clearly highlights the fact that fibre weaknesses were caused by alkali treatments. As discussed before, at $\alpha_{3}$, progressive matrix cracking and fibre buckling produced large strains on neighbouring fibres. At this stage, weak fibres could not take further strains developed from buckling and matrix cracking. As a result, fibres failed at lower loads and the composites exhibited lower $\alpha_{3}$ values.

3.2.2. Fibre Acetylation on Composites. Figure 8 shows a compressive stress-strain curve for $\mathrm{NaOH}$ pre-treated acetylated fibre composites, and their properties are summarised in Table 1. Table 1 shows that acetyl treatments exhibit around 23\% higher strength but 10\% lower failure strain compared to untreated samples. These results indicated that the acetyl groups were able to react with the hydroxyl groups that attached to the cellulose and developed strong bonding with the matrix [10]. During composite deformation, strong interfaces prevented fibre buckling and provided higher frictional resistance against compression loading. Due to this, the applied compressive load rapidly increased and reached its peak at relatively small elongations. This resulted in higher strengths but lower failure strains of the treated composites.

As can be observed from Table 1, the moduli in post buckling states were higher for acetylated composites compared to untreated samples. Higher moduli indicated strong fibre-matrix bonding that had taken place at the interface for the treated fibre composites. As a result, fibre buckling was restricted thus minimising the chances of matrix crack initiation. Similarly, acetylation on (4-10\%) $\mathrm{NaOH}$-treated fibre composites exhibited higher strengths, moduli $\left(\alpha, \alpha_{1}, \alpha_{2}\right.$, and $\left.\alpha_{3}\right)$, and breaking strains, compared to the (4-10\%) NaOH-treated samples. These results confirm that strong interface bonding was achieved due to the removal of fibre surface coverings (hemicellulose and lignin) in two consecutive treatment processes. During compression loading, fibres did not have sufficient space at their surrounding interfaces to develop fibre buckling which reduced the chances of matrix cracking. As a result, greater load transfers throughout the composites could be achieved and this justified higher compression properties of the composites.

3.2.3. Fibre Silanisation on Composites. Figure 9 illustrates compressive stress-strain curves for $\mathrm{NaOH}$ pre-treated silanised fibre composites, and their properties are summarised in Table 1. Table 1 shows that silane treatments exhibit around $17 \%$ lower compressive strength compared to untreated samples. Cellulose surfaces in the untreated samples were covered by hemicellulose and lignin coverings. Silane molecules were unable to penetrate the fibre surfaces to react with hydroxyl groups that were attached with the cellulose $[8,10]$. Rather, silane formed chemical linkages with the hydroxyl groups from the surface coverings (hemicellulose-lignin). Due to this, the silane did not facilitate strong couplings with fibres. Instead, it acted as an additional chemical layer on the fibre surfaces [10]. SEM image from Figure 6(f) shows an additional chemical layer on the silane-treated fibre surface. During compression loading, the chemical layers also generated buckling strain on the fibres and their surrounding interfaces, and thus contributed to the formation of matrix cracking. Fibre buckling and matrix cracking reduced the composites' load carrying capacities and thus exhibited lower compression properties.

It can be seen from Table 1 that $4 \% \mathrm{NaOH}$ pre-treated silanised samples exhibit higher compressive strengths compared to the original $4 \% \mathrm{NaOH}$-treated samples. This proved that the initial $4 \% \mathrm{NaOH}$ concentration was not strong enough to remove covering materials from the fibre surface effectively; rather, it exposed fibre hydroxyl groups. Silane molecules then reacted with these hydroxyl groups and formed silanols [8]. Silanols, in turn, formed strong couplings between fibre surfaces and the matrix. These chemical couplings promoted strong bonding at the interface. Strong interfaces enhanced the composites' load carrying capacities and produced higher compressive properties. SEM image in Figure 6(b) shows the presence of hemicellulose and lignin coverings on the fibre surface due to the initial $4 \% \mathrm{NaOH}$ treatment conditions. On the other hand, higher concentrations (6-10\%) of $\mathrm{NaOH}$ treatments removed hemicellulose and lignin coverings and their associated hydroxyl groups from the fibres. Furthermore, silane treatments did not leave sufficient hydroxyl groups to form silanols. As a result, chemical couplings at the interface became less capable of carrying compressive loads and thus lowered composite properties were exhibited.

3.2.4. Composites Failure Surface Analysis. Figure 10(a) shows a flat-wise view of composite failure surfaces. The image indicates that the reinforced fibres were banded on a composite surface plane at an angle to the loading direction, 


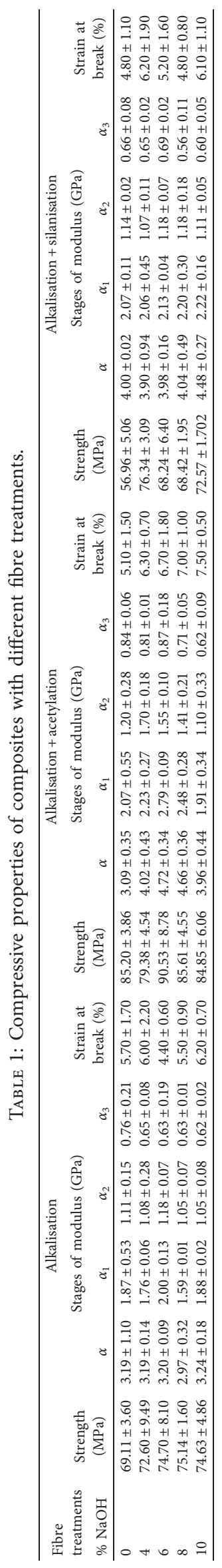




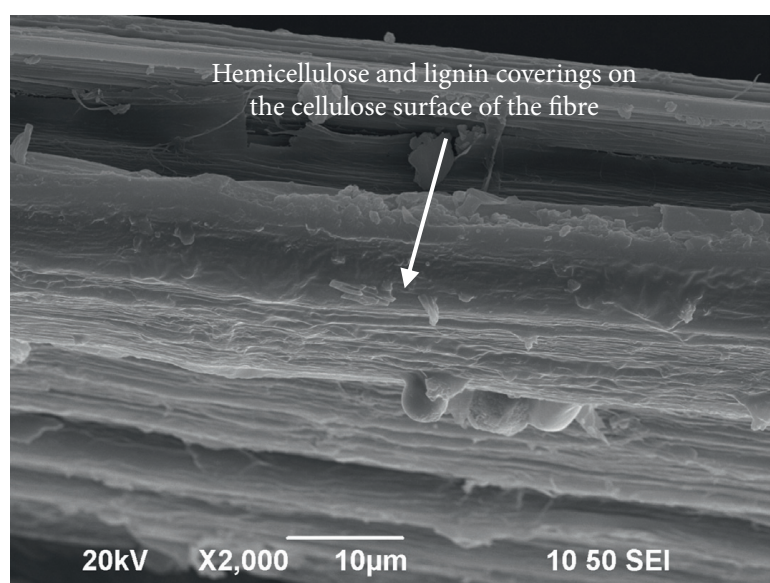

(a)

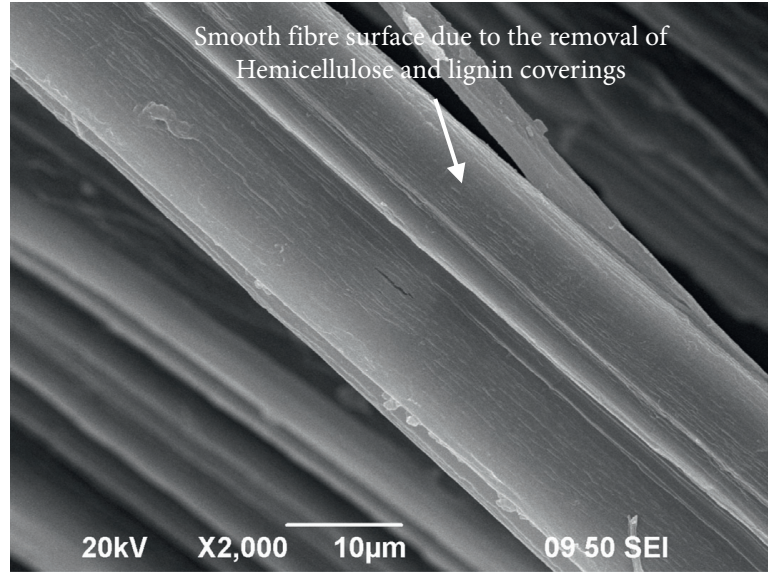

(c)

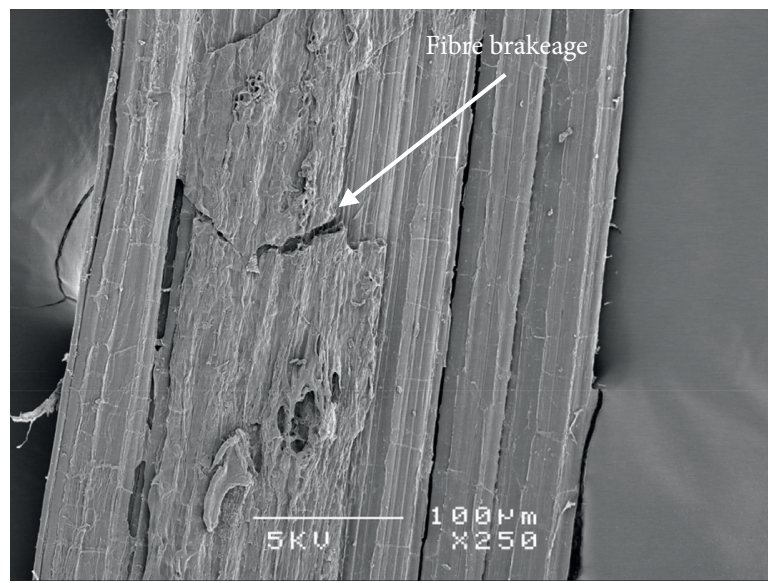

(e)

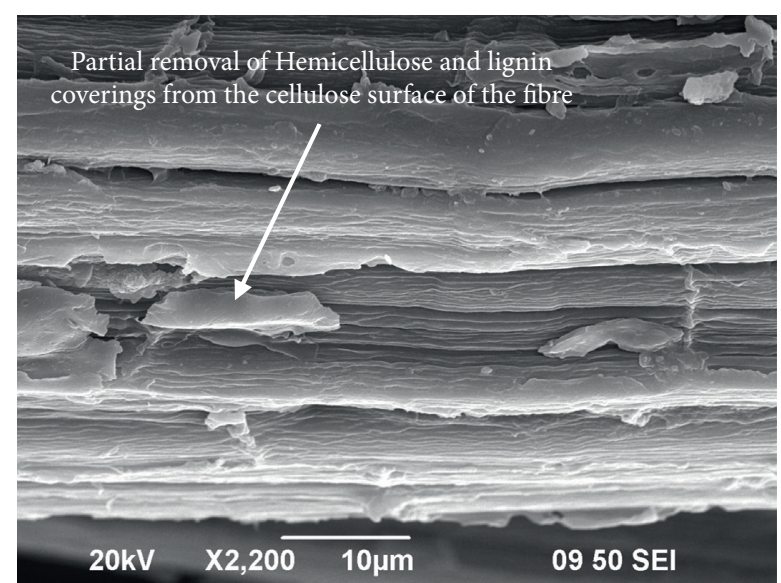

(b)

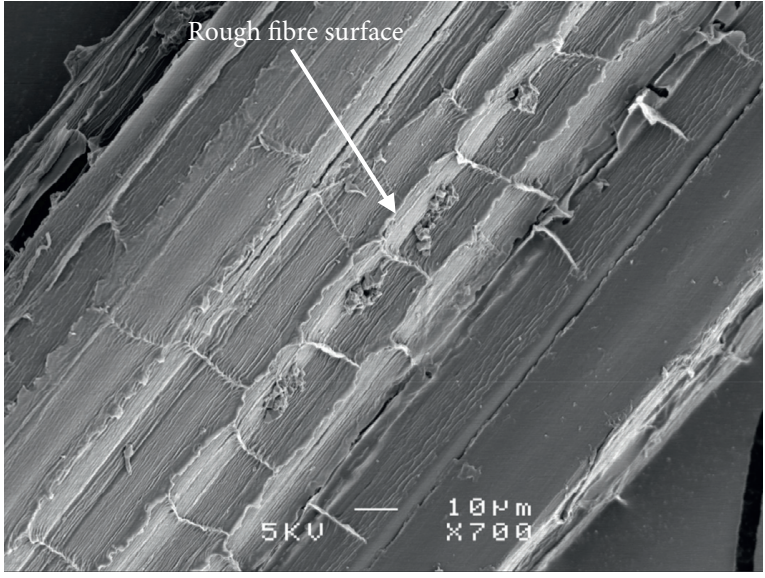

(d)

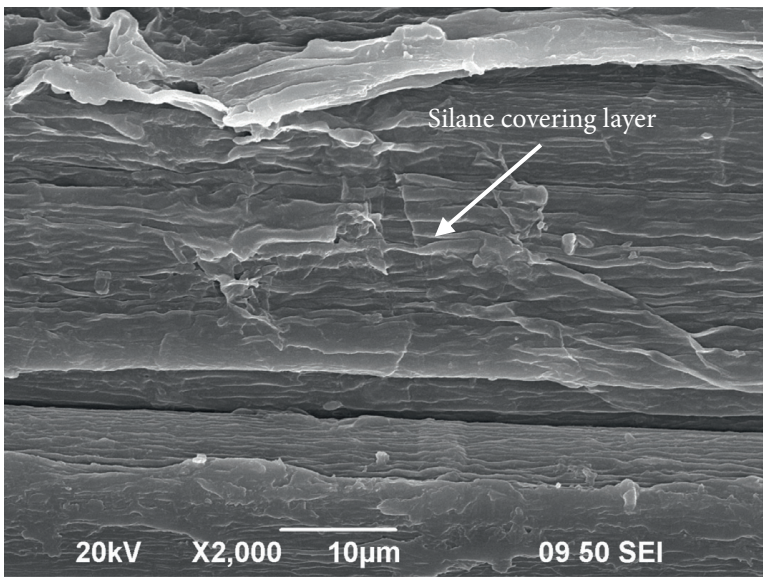

(f)

Figure 6: Chemically treated fibre surface: (a) $0 \% \mathrm{NaOH}$; (b) $4 \% \mathrm{NaOH}$; (c) $8 \% \mathrm{NaOH}$; (d) acetylation; (e) $8 \% \mathrm{NaOH}+$ acetylation; (f) silane.

and the fibres' bends were spread over the composite surface. This section of bent fibres is known as a kink band. Kink bands develop due to fibres buckling $[35,36]$. This band forms in the post-buckling state when the composites fail gradually under large deformations (ductile failure) [36, 37]. Figure 10(b) illustrates the failure surface of silane-treated composites. It shows shear bands surrounded by the interface which has developed cracks. This indicated that weak interface bonding was prevalent facilitating the development of fibre buckling more easily in the matrix. In addition, shear bands formed due to shear displacement of the buckled fibres. Progressive fibre buckling initiated interface cracking and generated shear bands on failure surfaces. Further observations of failure samples showed 


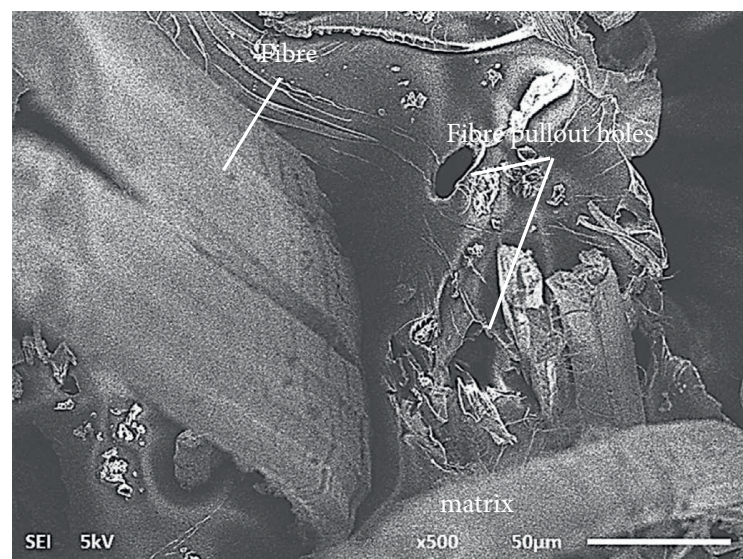

(a)

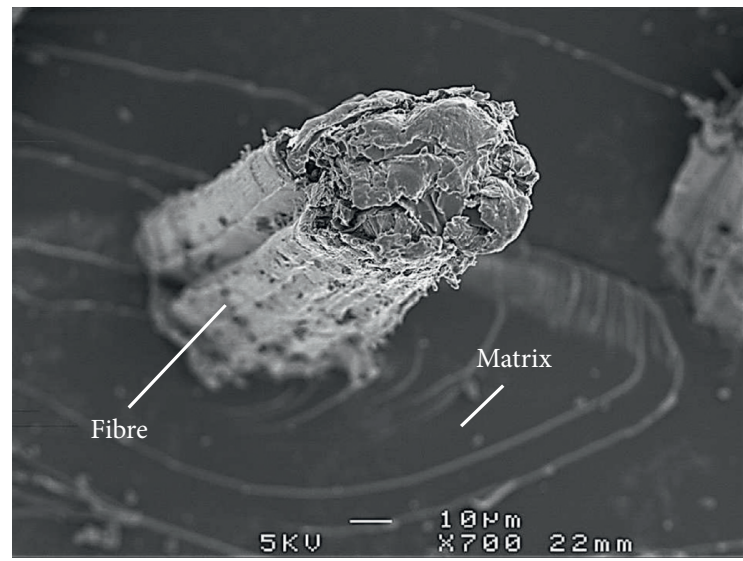

(c)

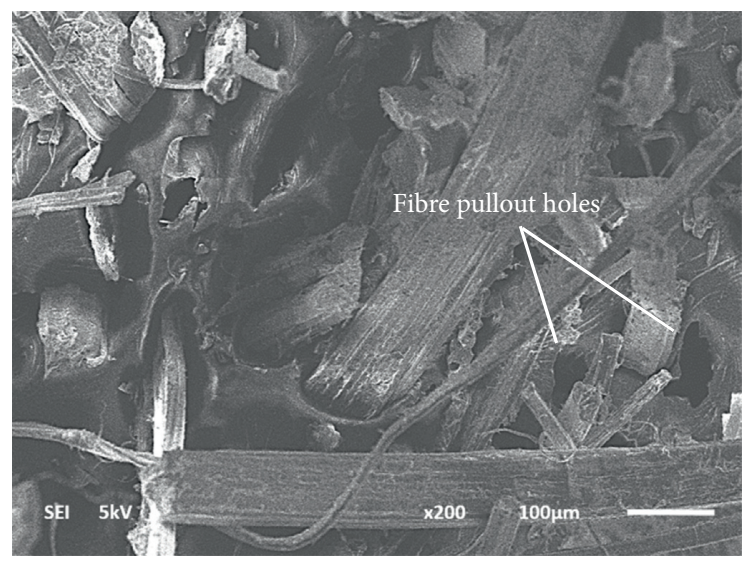

(e)

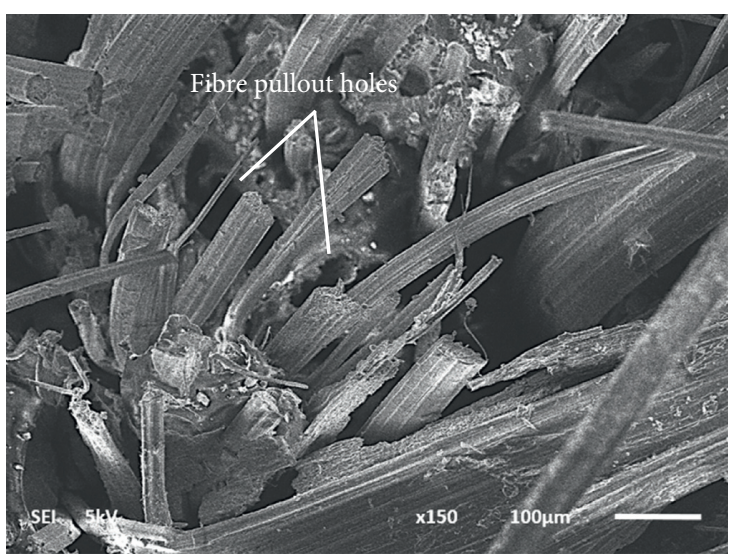

(b)

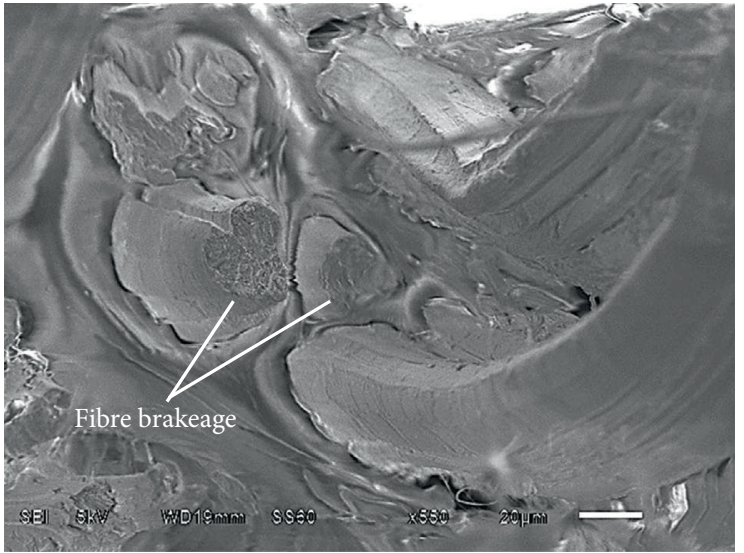

(d)

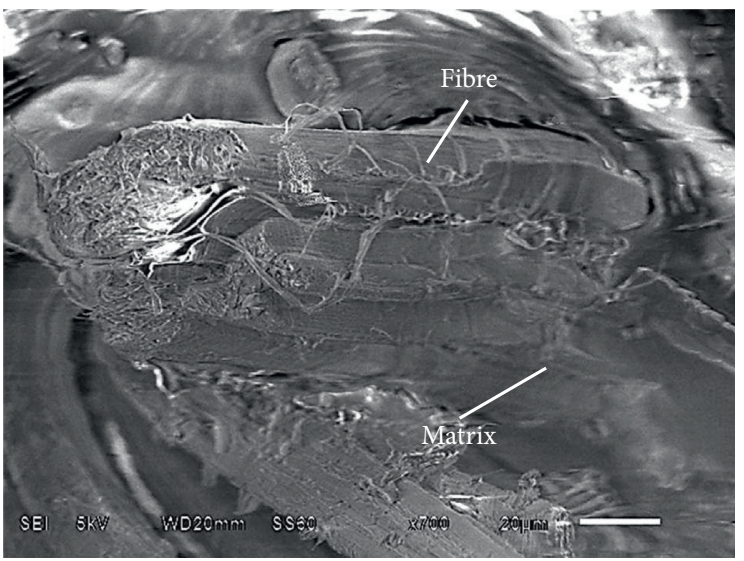

(f)

Figure 7: Chemically treated fibre composite samples: (a) $0 \% \mathrm{NaOH}$; (b) $4 \% \mathrm{NaOH}$; (c) $6 \% \mathrm{NaOH}$; (d) acetylated; (e) silane; (f) $4 \% \mathrm{NaOH}$ pretreated silane.

fractured fibres. This was again due to poor interface bonding which facilitated maximum fibre buckling. As a result, fibres reached a critical strength level sufficient to promote fibre fracturing. On the other hand, Figure 10(c) shows multiple interface cracks on the alkalised composites. Compression properties decreased rapidly as the crack sizes increased. Similar failure modes were also observed for acetylated composites (Figure 10(d)). From Figures 10(c) and $10(\mathrm{~d})$, it can be observed that the number and width of the crack openings for alkalised composites was higher compared to the acetylated fibre composites. This indicated that acetylated fibres formed stronger bonds with the matrix and had higher compression properties. In addition, there was no evidence of fibres fracturing on the failure surface of alkalised and acetylated composites. This demonstrated that fibre buckling along the interface was insufficient to cause 


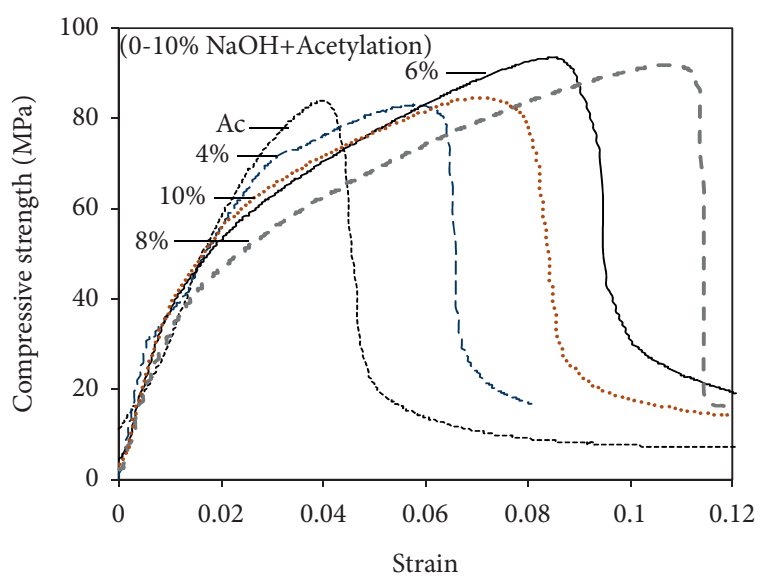

Figure 8: Compressive stress-strain curves of acetylated fibre composites.

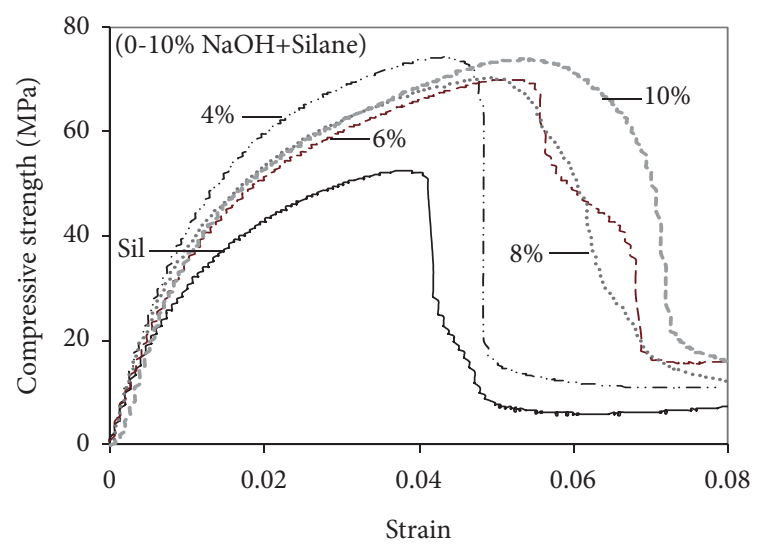

FIgURE 9: Compressive stress-strain curves of silanised fibre composites.

the fibres to fail. This again proved that strong interface bonding resulted through the treatment of fibres.

3.3. Flexural Properties of Composites. Flexural properties of composites were measured through conventional threepoint bending tests. Flexural load was applied perpendicularly to the fibre direction. Initially, the loading nose came in contact with the upper surface of the specimen. Load was transferred from the elastic matrix to the fibres. Under incremental loading, the fibres started to bend, and strained into the matrix. Bent fibres generated further strains to neighbouring fibres and caused them to bend also [38]. This led to fibre-matrix interface instability and generated disproportionately high stresses on the matrix. As a result, the matrix shifted from elastic to plastic deformation and initiated damage of the composites. During flexural testing, the top and bottom faces of the specimen mid-section experienced compressive and tensile stresses. Compressive stresses produced large longitudinal tensile stresses on the lower surfaces of the specimen. The combination of vertical compressive stress and longitudinal tensile stress produced shear stresses [39, 40]. Figure 11 shows flexural failure modes of the tested samples. From this figure, it can be observed that considerable damage appeared on the compression side of the specimen. An upper shear crack is visible just below the compressive crack. The compression cracks propagate downward causing the expansion of the upper shear cracks. Moreover, the compression and upper shear cracks produced the tension crack at the specimen's bottom layer. A shear crack is also visible at the bottom face of the specimen just above the tension crack. Tensile failure of the outermost fibres on the tension side is observed.

Figure 12 presents a flexural stress-strain curve for untreated fibre composites. The curve shows that the material response was linear (elastic-linear) up to the strength of around $80 \mathrm{MPa}$ and strain of 0.0095 , where both fibre and matrix behaved linearly. The linear elastic response was marked by $\alpha$. Afterwards, the curve deviated from this linear proportionality and a geometric nonlinear response went up to a stress of about $190 \mathrm{MPa}$ and the failure stress point was reached. At this stage, the curve diverged in several points with different stages of modulus $\left(\alpha_{1}, \alpha_{2}, \alpha_{3}\right)$ values. The shape of the stress-strain curves indicated ductile failure. This type of failure showed that crack initiation took place at approximately regular intervals. Due to this, modulus values diverged at several points on the curve.

3.3.1. Fibre Alkalisation on Composites. Figure 13 shows a flexural stress-strain curve for alkalised fibre composites, and their properties are summarised in Table 2. From Table 2, it was observed that lower concentrations (4\%) of $\mathrm{NaOH}$ treatments on the fibres reduced composite flexural properties (strengths, modulus $(\alpha)$, and failure strain), compared to untreated samples. As treatment concentrations increased $(6-10 \% \mathrm{NaOH})$, flexural properties also increased in comparison to $4 \% \mathrm{NaOH}$-treated samples. As discussed in previous sections, lower treatment concentrations $(4 \% \mathrm{NaOH})$ produced weak interface bonding between the fibres and matrix. Weak bonding reduced the matrix support to the fibres which ultimately lowered frictional resistance at their interface. During flexural loading, compressive cracking was initiated at weak interfaces due to fibres bending in the matrix. Compressive cracks generated further strains on neighbouring interfaces. The bottom surface of the specimens experienced relatively higher tensile stresses due to the contribution of progressive compressive cracks. The higher tensile stresses and the progressive compressive cracks collectively caused tensile failure of the fibre and thus failure of overall composites. As a result, weak interface bonding reduced the composite's ultimate load-carrying capacities and consequently reduced its strength, strain, and modulus values. SEM image in Figure 7(b) shows holes where fibres were pulled out from the matrix, indicating that fibre sliding took place due to weak interfacial bonding in case of $4 \% \mathrm{NaOH}$ treatment case. This was due to the presence of hemicelluloses and lignin constituents on the fibre surface (Figure 6(b)) which resist the stress transferred from the matrix to the fibre. However, at higher treatment concentrations $(6-10 \% \mathrm{NaOH})$, composite strengths increased 


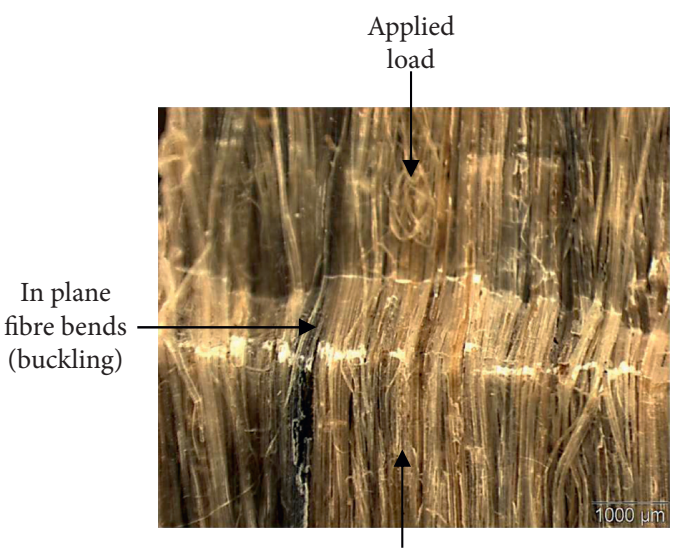

(a)

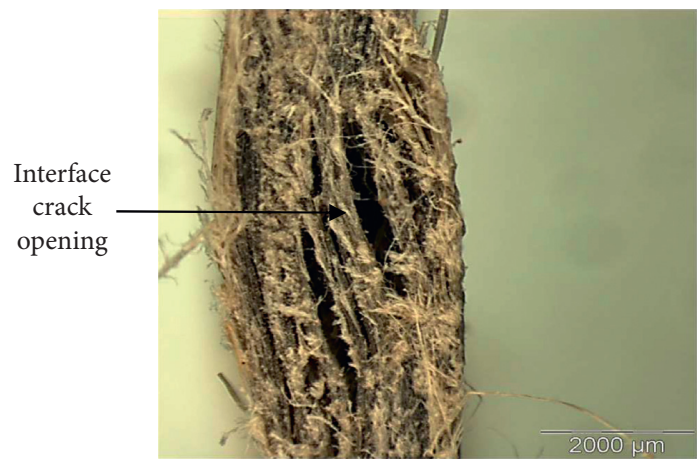

(c)

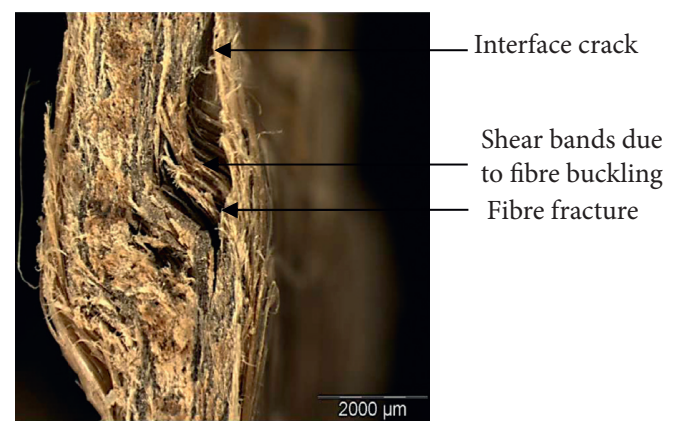

(b)

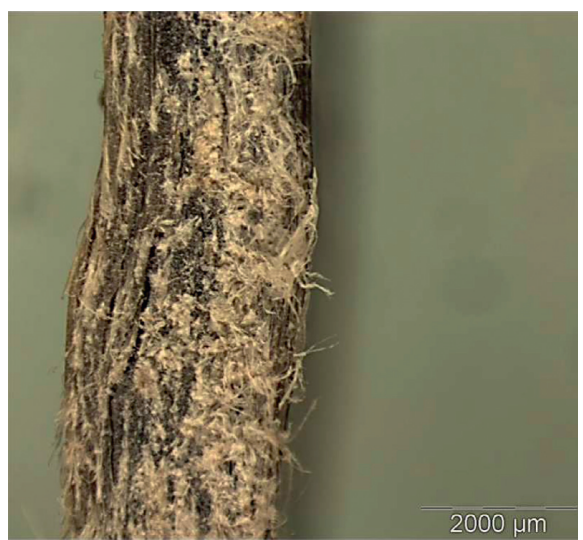

(d)

FIgURE 10: Microscopic images of failure surface for (a) flat-wise view (b) silanised (c) alkalised (d) acetylated composites.

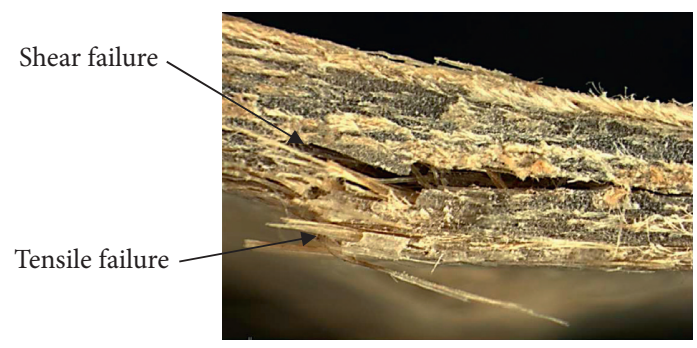

(a)

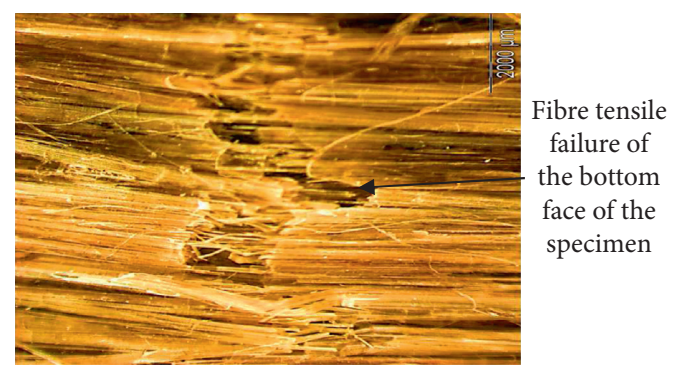

(b)

Figure 11: Flexural failure modes of tested samples.

from around $175 \mathrm{MPa}$ to $220 \mathrm{MPa}$, compared to $4 \% \mathrm{NaOH}-$ treated samples. The enhanced composite properties were primarily governed by the higher degree of interface bonding which facilitated greater load transfer action of the samples. This was possibly due to the fact that higher $\mathrm{NaOH}$ concentrations effectively removed the hemicellulose and lignin coverings from the fibre surface. As a result, more accessible cellulose surfaces were exposed to matrix adhesion and thus produced strong interface bonding.

Beyond optimum concentration levels, fibres began losing their strength. During composite deformations, weak fibres gradually deformed at the strong fibre-matrix interfaces. From Table 2, it can be seen that higher concentrations $(6-10 \%)$ of $\mathrm{NaOH}$ treatments increase the composites' failure strain. This was indicative of weak fibre deformation at their strong interface. Thus, the materials were able to sustain large deflections before the break. Similar observations were made from Table 2 where the moduli $\left(\alpha, \alpha_{1}\right)$ also decreased at higher treatment concentrations $(6-10 \% \mathrm{NaOH})$. At $\alpha$ and $\alpha_{1}$, interface cracks developed and propagated throughout the matrix. Weak fibres gradually lost their load-carrying capacities to bridge the matrix cracks and failed under large deformations, thus reducing composite moduli. 


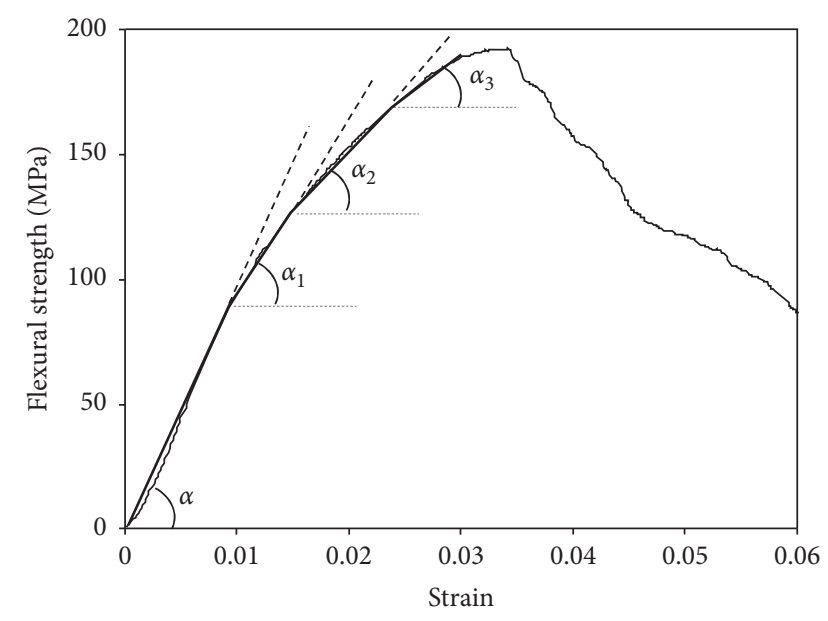

FIgURE 12: Flexural stress-strain curve of the fibre composite.

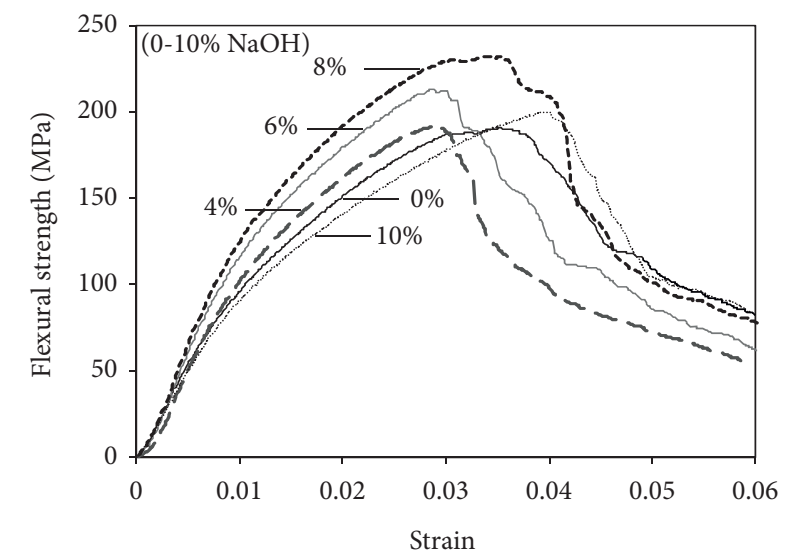

FIGURE 13: Flexural stress-strain curves of alkalised fibre composites.

3.3.2. Fibre Acetylation on Composites. Figure 14 shows a flexural stress-strain curve of $\mathrm{NaOH}$ pre-treated acetylated fibre composites, and their properties are summarised in Table 2. From Table 2, it is observed that acetyl treatments on untreated fibres $(0 \% \mathrm{NaOH})$ increase composites' strength from $191 \mathrm{MPa}$ to $255 \mathrm{MPa}$, which is an increase of $30 \%$. Similarly, composites' moduli also increase $(\alpha=48 \%$, $\alpha_{1}=63 \%, \alpha_{2}=53 \%, \alpha_{3}=55 \%$ ), but the failure strain is decreased when compared to untreated samples. These results indicated that acetylation removed the hemicellulose and lignin coverings and also esterified hydroxyl groups present within the fibre. Consequently, interface adhesion increased, allowing the composites to carry greater flexural loads at relatively small elongations. As a result, the flexural properties of the acetylated composites increased. SEM images show that acetylated fibre exhibited rough surface (Figure 6(d)) compared to the untreated fibre surface (Figure 6(a)). Figure 7(d) shows good fibre matrix interface bonding due to the acetyl treatment compared to the untreated fibre composites sample (Figure 7(a)).

Acetyl treatments on the $4 \% \mathrm{NaOH}$ pre-treated sample also improved composites' strength and moduli compared to the $4 \% \mathrm{NaOH}$-treated samples. The hydroxyl groups presented on the pre-treated fibre were esterified during acetyl treatments. Also, the hemicellulose and lignin constituents were removed through acetylation. Due to this, cellulose surfaces were more accessible for matrix adhesion which promoted strong fibre-matrix interface bonding. As a result, the application of two consecutive treatments on the fibres improved the composites' properties. However, at higher $(6-10 \%) \mathrm{NaOH}$ pre-treatment concentrations, further acetylation caused greater removal of fibre surface coverings, thus enhancing interface bonding. Fibres became weaker in strength due to the removal of hemicellulose and lignin covering materials. SEM image in Figure 6(e) shows acetyl treatment on the $\mathrm{NaOH}$ pre-treated fibre resulted in fibre breakage throughout its length. This indicates that fibre weakness was caused due to the two consecutive treatment processes. During flexural loading, weak fibres transferred compressive loads effectively through strong interfaces but suddenly failed under tensile loading. These observations can be further supported by the compressive properties (Table 1) of the acetylated composites. Thus, 6-10\% $\mathrm{NaOH}$ pre-treated acetylated samples exhibited lower flexural strength but higher modulus compared to the $\mathrm{NaOH}$-treated samples.

3.3.3. Fibre Silanisation on Composites. Figure 15 shows a flexural stress-strain curve for silanised fibre composites, and their properties are summarised in Table 2. From Table 2, it is observed that silane treatments on the untreated fibres reduced the composite's flexural strengths and moduli. These results indicated that silane molecules were unable to penetrate the untreated fibre surfaces due to the presence of surface coverings. As a result, weak interface bonding took place and the composites failed with lower flexural properties compared to the untreated sample. Figure 7(e) shows weak interface bonding between the silane-treated fibre and matrix which is similar to failure surfaces of untreated fibre composites (Figure 7(a)). Fibre pull-out holes appearing on silane-treated samples indicate that weak interfacial bonding took place. However, silane treatments on the $4 \% \mathrm{NaOH}$ pre-treated samples exhibited higher strength compared to the $4 \% \mathrm{NaOH}$-treated samples. The original $4 \% \mathrm{NaOH}$-treated sample shows fibre pull-out holes and weak interfacial bonding (Figure 7(b)). On the other hand, Figure 7(f) shows that good interfacial bonding took place in case of silane treatment on the $4 \% \mathrm{NaOH}$ pretreated fibre samples. This again proved that silane molecules formed strong couplings with the pre-treated fibres in the presence of fibre hydroxyl groups. This provided strong bonding between the fibres and matrix, and the composites were able to transfer greater flexural loadings compared to the $4 \% \mathrm{NaOH}$-treated samples. As pre-treatment concentrations $(6-10 \% \mathrm{NaOH})$ increased, fibres lost their hydroxyl groups and silane molecules could not achieve sufficient reaction sites to form strong couplings with the fibres. This created weaknesses at the fibre-matrix interface. As a result, silanisation on the pre-treated fibres exhibited lower strengths and moduli compared to the 6-10\% $\mathrm{NaOH}-$ treated samples. 


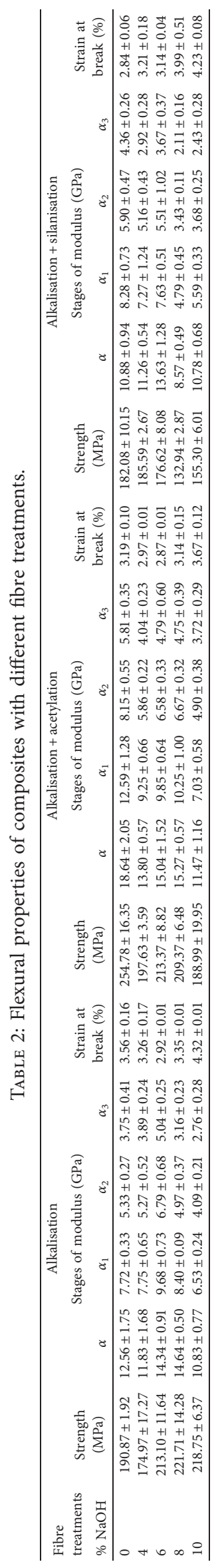




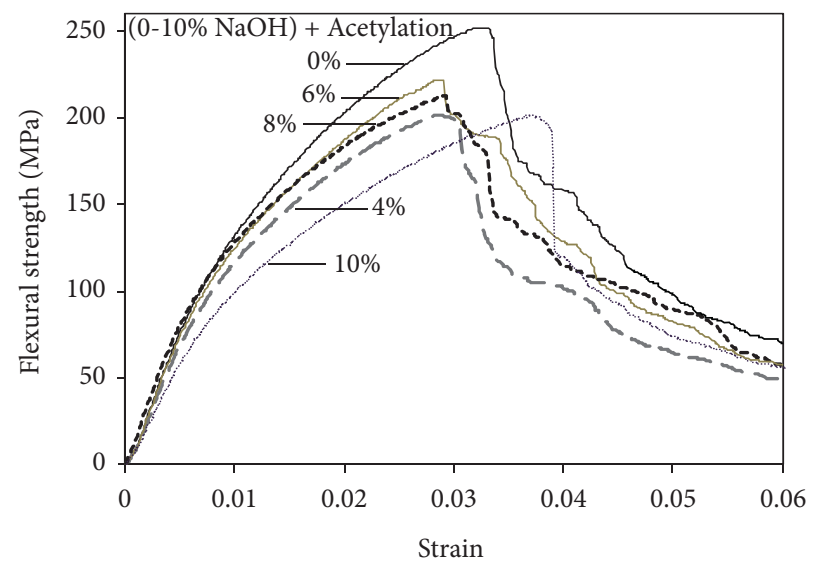

FIgURE 14: Flexural stress-strain curves of acetylated fibre composites.

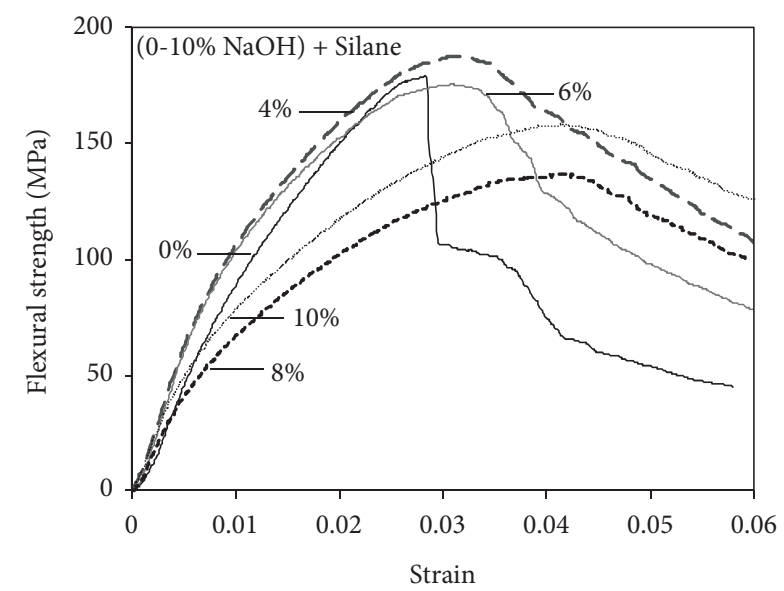

Figure 15: Flexural stress-strain curves of silanised fibre composites.

From the above analysis, it can be stated that higher concentrations $(6-10 \%)$ of $\mathrm{NaOH}$ treatments on untreated fibres improved composite flexural properties. Fibre surface coverings were removed at higher treatment concentrations, which facilitated stronger bonding with the matrix and thus exhibited higher properties. However, acetyl treatments effectively removed fibre surface coverings and also esterified hydroxyl groups from the $(0-4 \%) \mathrm{NaOH}$ pre-treated fibres. Stronger interface bonding was achieved and composites exhibited higher flexural properties. Therefore, higher $(6-10 \%) \mathrm{NaOH}$ concentrations weakened fibres and further acetylation caused more losses of fibre strength. Consequently, at higher pre-treatment conditions, acetylated samples exhibited lower strengths. Similarly, silane treatments on the alkali pre-treated fibre composites initially showed higher strengths, but at higher pre-treatment conditions the samples exhibited lower properties compared to the $\mathrm{NaOH}$-treated samples. This was due to the reduced amounts of hydroxyl groups being present on the pretreated fibres forming weak silane couplings with the fibre. As a result, weak interface bonding took place and composites exhibited lower flexural properties.

\section{Conclusion}

The treatment effects on interface bonding in long unidirectional hemp fibre polyester composites were characterised by performing property analysis through compression and bending tests. The structural composition and thermal decomposition of the fibres after treatments were investigated through DSC analyses. From the analysis, the following conclusions are made for these experimental studies.

(i) DSC analysis on the fibre constituents (cellulose, hemicellulose, and lignin) confirmed that the thermal stability of hemicellulose was lowered compared to the cellulose and lignin constituents. Also, hemicellulose was the primarily responsible fibre constituent to absorb moisture from the atmosphere. Alkalised and acetylated fibres showed higher thermal stability and lower moisture absorption capability compared to the untreated fibre due to the partial removal of hemicellulose and lignin constituents. For silanised fibre, silane formed couplings with the fibre constituents and provided a covering on the fibres thus protecting them from thermal degradations.

(ii) Compression test on the alkali-treated fibre composites showed approximately $9 \%$ increase and alkali pre-treated acetylated fibre composite showed around $30 \%$ increase in strength properties compared to the untreated case. These results indicate that $\mathrm{NaOH}$ treatments and acetylation could remove the hemicellulose and lignin coverings from the fibre surface. The removal of the fibre surface coverings facilitated strong interfacial bonding with matrix materials. However, silane treatment showed around $17 \%$ lower compressive strength compared to untreated samples. Sinale molecule covered the fibre surface instead of removing the hemicellulose and lignin covering from the cellulose surface. Due to this, the silane did not facilitate strong couplings with fibres and thus showed lower composite strength properties. 
(iii) Flexure test on the alkali treated fibre composites showed around $16 \%$ increase in strength and modulus properties compared to the untreated case. Similarly, acetylated fibre composite showed around $33 \%$ increase in strength and $48 \%$ increase in modulus properties. However, silane treatment showed $5 \%$ decrease in strength and $13 \%$ decrease in modulus properties. These results illustrate further evidence of the strong fibre matrix interfacial bonding due to the removal of hemicellulose and lignin coverings from the fibre surface due to the $\mathrm{NaOH}$ and acetylation treatment.

(iv) The compressive and flexural test revealed that $4 \%$ $\mathrm{NaOH}$ treatments exhibited the lowest strength properties. These results indicated that the initial $4 \%$ $\mathrm{NaOH}$ concentration was insufficient to cause effective removal of the hemicellulose and lignin binders from the cellulose surfaces. Instead, treatments facilitated hydroxyl groups' absorption of atmospheric moisture. The presence of moisture in the fibre led to poor bonding with the matrix. The weak interface bonding reduced the composites' load-carrying capacity and thus the composites failed at lower strength.

(v) An analysis of fibre surface morphology revealed that cellulose provided the main structural basis for the fibre and had the cleanest surface appearances, whilst hemicellulose and lignin had gummy appearances and adhered onto the cellulose surface. The prevalence of fibre constituents was observed on the untreated fibre surfaces. Alkalised and acetylated fibre surfaces exhibited clean distinctive microfibril separation. Alternatively, silanised fibre surfaces exhibited a visible chemical layer.

Among all reinforcing fibre treatments, acetylated composites showed the best results in terms of strength, failure strain, and modulus. Alkali treatments also exhibited similar composite properties. Higher composite properties indicated that treatments were effective in removing fibre surface coverings to provide strong interface bonding. Due to the presence of fibre surface coverings on untreated fibres, silane molecules were not able to form effective bonding with the fibre surfaces. As a consequence, weak bonding between the fibres and matrix took place and silane-treated composites showed weaker properties compared to the alkalised and acetylated samples. Based on the discussions above, it can be concluded that chemical treatments on hemp fibres can enhance the mechanical strength of its composites. Improvements are governed by the removal of hemicellulose and lignin from the fibre, which provides a platform for better chemical reactions between fibres and matrix.

\section{Data Availability}

The data used to support the findings of this study are available from the corresponding author upon request.

\section{Disclosure}

This research paper is part of the $\mathrm{PhD}$ project and dissertation, "Effects of Chemical Treatments on Hemp Fibre Reinforced Polyester Composites," conducted by the first author.

\section{Conflicts of Interest}

The authors declare that there are no conflicts of interest regarding the publication of this paper.

\section{Acknowledgments}

This project was supported by the Department of Education and Knowledge (ADEK, AARE17-168) and the University of Southern Queensland. The authors are grateful to Ali Naim Khurshid and Wayne Crowell for providing helpful suggestions regarding this study.

\section{References}

[1] M. Ramesh, C. Deepa, G. R. Arpitha, and V. Gopinath, "Effect of hybridization on properties of hemp-carbon fibrereinforced hybrid polymer composites using experimental and finite element analysis," World Journal of Engineering, vol. 16, no. 2, pp. 248-259, 2019.

[2] M. M. Kabir, H. Wang, K. T. Lau, and F. Cardona, "Chemical treatments on plant-based natural fibre reinforced polymer composites: an overview," Composites Part B: Engineering, vol. 43, no. 7, pp. 2883-2892, 2012.

[3] C. Campana, R. Leger, R. Sonnier, L. Ferry, and P. Ienny, "Effect of post curing temperature on mechanical properties of a flax fiber reinforced epoxy composite," Composites Part A: Applied Science and Manufacturing, vol. 107, pp. 171-179, 2018.

[4] M. M. Kabir, H. Wang, K. T. Lau, F. Cardona, and T. Aravinthan, "Mechanical properties of chemically-treated hemp fibre reinforced sandwich composites," Composites Part B: Engineering, vol. 43, no. 2, pp. 159-169, 2012.

[5] R. Bhoopathi, M. Ramesh, M. Naveen Kumar, P. Sanjay Balaji, and G. Sasikala, "Studies on mechanical strengths of hempglass fibre reinforced epoxy composites," IOP Conference Series: Materials Science and Engineering, vol. 402, no. 1, Article ID 012083, 2018.

[6] M. M. Kabir, M. Y. Al-Haik, S. H. Aldajah, K. T. Lau, and H. Wang, "Impact properties of the chemically treated hemp fibre reinforced polyester composites," Fibers and Polymers, vol. 21, no. 9, pp. 2098-2110, 2020.

[7] H. A. Aisyah, M. T. Paridah, S. M. Sapuan et al., "A Comprehensive review on advanced sustainable woven natural fibre polymer composites," Polymers, vol. 13, no. 3, p. 471, 2021.

[8] M. M. Kabir, H. Wang, K. T. Lau, and F. Cardona, "Tensile properties of chemically treated hemp fibres as reinforcement for composites," Composites Part B: Engineering, vol. 53, pp. 362-368, 2013.

[9] A. K. Bledzki and J. Gassan, "Composites reinforced with cellulose based fibres," Progress in Polymer Science, vol. 24, no. 2, pp. 221-274, 1999.

[10] M. M. Kabir, H. Wang, K. T. Lau, and F. Cardona, "Effects of chemical treatments on hemp fibre structure," Applied Surface Science, vol. 276, pp. 13-23, 2013. 
[11] L. Sisti, G. Totaro, M. Vannini et al., "Evaluation of the retting process as a pre-treatment of vegetable fibers for the preparation of high-performance polymer biocomposites," Industrial Crops and Products, vol. 81, pp. 56-65, 2016.

[12] J. C. F. Walker, Primary Wood Processing: Principles and Practice, Springer, Verlag, Netherlands, 2nd edition, 2006.

[13] B. Wang, S. Panigrahi, L. Tabil, and W. Crerar, "Pre-treatment of flax fibers for use in rotationally molded biocomposites," Journal of Reinforced Plastics and Composites, vol. 26, no. 5, pp. 447-463, 2007.

[14] S. O. Amiandamhen, M. Meincken, and L. Tyhoda, "Natural fibre modification and its influence on fibre-matrix interfacial properties in biocomposite materials," Fibers and Polymers, vol. 21, no. 4, pp. 677-689, 2020.

[15] M. M. Kabir, Effects of Chemical Treatments on Hemp Fibre Reinforced Polyester Composites, Doctoral dissertation, University of Southern Queensland, Toowoomba, Australia, 2012.

[16] B. N. Dash, A. K. Rana, S. C. Mishra, H. K. Mishra, S. Nayak, and S. Tripathy, "Novel low-cost jute-polyester composite. II. SEM observation of the fractured surfaces," Polymer-Plastics Technology and Engineering, vol. 39, no. 2, pp. 333-350, 2000.

[17] M. J. John and R. D. Anandjiwala, "Recent developments in chemical modification and characterization of natural fiberreinforced composites," Polymer Composites, vol. 29, no. 2, pp. 187-207, 2008.

[18] X. Li, L. Tabil, and S. Panigrahi, "Chemical treatments of natural fiber for use in natural fiber-reinforced composites: a review," Journal of Polymers and the Environment, vol. 15, no. 1, pp. 25-33, 2007.

[19] R. Bhoopathi and M. Ramesh, "Influence of eggshell nanoparticles and effect of alkalization on characterization of industrial hemp fibre reinforced epoxy composites," Journal of Polymers and the Environment, vol. 28, pp. 2178-2190, 2020.

[20] L. Y. Mwaikambo, N. Tucker, and A. J. Clark, "Mechanical properties of hemp-fibre-reinforced Euphorbia composites," Macromolecular Materials and Engineering, vol. 292, no. 9, pp. 993-1000, 2007.

[21] D. Ray, B. Sarkar, A. Rana, and N. Bose, "Effect of alkali treated jute fibres on composite properties," Bulletin of Materials Science, vol. 24, no. 2, pp. 129-135, 2001.

[22] A. Bledzki, A. Mamun, M. Lucka, and V. Gutowsk, "The effects of acetylation on properties of flax fibre and its polypropylene composites," Express Polymer Letters, vol. 2, no. 6, pp. 413-422, 2008.

[23] L. Y. Mwaikambo and M. P. Ansell, "The effect of chemical treatment on the properties of hemp, sisal, jute and kapok fibres for composite reinforcement," Die angewandte makromolekulare Chemie, vol. 272, pp. 108-116, 1999.

[24] K. M. Ilomaki, Adhesion between Natural Fibers and Thermosets, Master thesis, Tampere University of Technology, Tampere, Finland, 2012.

[25] H. Khalil, H. Ismail, H. Rozman, and M. Ahmad, "The effect of acetylation on interfacial shear strength between plant fibres and various matrices," European Polymer Journal, vol. 37, no. 5, pp. 1037-1045, 2001.

[26] A. Mohanty, M. Misra, and L. T. Drzal, Natural Fibers, Biopolymers, and Biocomposites, CRC Press Taylor \& Francis Group, Boca Raton, FL, USA, 2005.

[27] N. A. Fleck and D. Liu, "Microbuckle initiation from a patch of large amplitude fibre waviness in a composite under compression and bending," European Journal of Mechanics A: Solids, vol. 20, no. 1, pp. 23-38, 2001.
[28] P. Jelf and N. Fleck, "Compression failure mechanisms in unidirectional composites," Journal of Composite Materials, vol. 26, no. 18, pp. 2706-2726, 1992.

[29] J. D. Menczel, L. Judovits, R. B. Prime, H. E. Bair, M. Reading, and S. Swier, "Differential scanning calorimetry (DSC)," in Book Thermal Analysis of Polymers: Fundamentals and Applications, J. D. Menczel and R. B. Prime, Eds., pp. 7-239, Wiley, New York, NY, USA, 2009, https://www.wiley.com/en-au/Thermal+ Analysis+of+Polymers\%3A+Fundamentals+and+Applicationsp-9780471769170.

[30] R. Ball, A. McIntosh, and J. Brindley, "Feedback processes in cellulose thermal decomposition: implications for fireretarding strategies and treatments," Combustion Theory and Modelling, vol. 8, no. 2, pp. 281-291, 2004.

[31] U. Reh, G. Kraepelin, and I. Lamprecht, "Use of differential scanning calorimetry for structural analysis of fungally degraded wood," Applied and Environmental Microbiology, vol. 52, no. 5, pp. 1101-1106, 1986.

[32] S. Ranganathan and P. R. Mantena, "Axial loading and buckling response characteristics of pultruded hybrid glassgraphite/epoxy composite beams," Journal of Reinforced Plastics and Composites, vol. 22, no. 7, pp. 671-679, 2003.

[33] N. Fleck, P. Jelf, and P. Curtis, "Compressive failure of laminated and woven composites," Journal of Composites Technology and Research, vol. 17, no. 3, pp. 212-220, 1995.

[34] C. Gonzalez and J. Lorca, "Mechanical behaviour of unidirectional fiber-reinforced polymers under transverse compression: microscopic mechanisms and modeling," Composites Science and Technology, vol. 67, no. 13, pp. 2795-2806, 2007.

[35] F. M. Jensen, B. Falzon, J. Ankersen, and H. Stang, "Structural testing and numerical simulation of a $34 \mathrm{~m}$ composite wind turbine blade," Composite Structures, vol. 76, no. 1-2, pp. 52-61, 2006.

[36] H. Azzam, "Compressive properties of stretch-broken carbon fiber (SBCF)/polyamide 12 commingled unidirectional composites," Journal of Engineering and Applied Science, vol. 54, no. 4, p. 409, 2007.

[37] J. Cho, J. Chen, and I. Daniel, "Mechanical enhancement of carbon fiber/epoxy composites by graphite nanoplatelet reinforcement," Scripta Materialia, vol. 56, no. 8, pp. 685-688, 2007.

[38] Z. M. Huang, "Progressive flexural failure analysis of laminated composites with knitted fabric reinforcement," $M e$ chanics of Materials, vol. 36, no. 3, pp. 239-260, 2004.

[39] C. C. Jeng and M. Chen, "Flexural failure mechanisms in injection-moulded carbon fibre/PEEK composites," Composites Science and Technology, vol. 60, no. 9, pp. 1863-1872, 2000.

[40] W. Lu, P. Kao, and A. Su, "Flexural failure of unidirectional carbon/epoxy composites: effects of interleaving and flexural rate," Journal of Polymer Research, vol. 5, no. 3, pp. 133-142, 1998. 